\title{
Nursing Students' Awareness, Knowledge and Attitudes on Child Abuse
}

\author{
Hyun-Jung Kim ${ }^{1}$, Dahye Park ${ }^{2}$ \\ ${ }^{1}$ Professor, Department of Nursing, Daewon University College, Jecheon-si, Chungbuk, 27135, Korea, \\ ${ }^{2}$ Professor, Department of Nursing, Semyung University, Jecheon-si, Chungbuk, 27136, Korea
}

\begin{abstract}
Background/Objectives: This study was designed to explore nursing students' awareness, knowledge, attitude on child abuse.

Method/Statistical analysis: The descriptive research design was conducted by administering online questionnaire to 299 nursing students at two university in J city. Data analysis was performed using SPSS WIN 25.0 program.

Findings: The mean scores of child abuse awareness, knowledge and attitude were $175.42 \pm 10.69,3.89 \pm 1.83$ and $28.94 \pm 6.57$ respectively. Awareness, knowledge and attitude on child abuse were significantly positively correlated. In addition, the number of education on child abuse was positively correlated with awareness, knowledge and attitude on child abuse. Factors influencing child abuse attitude were frequency of child abuse education, awareness and knowledge $\left(\mathrm{R}^{2}=.222\right)$.

Improvements/Applications: Based on this results, the development of education programs and guidelines to help nursing students detect child abuse and improve reporting rates is important. Thus, we suggest that nursing students be provided with educational protocol for detection, including report of child abuse.
\end{abstract}

Keywords: ChildAbuse, Awareness, Knowledge, Attitudes, Nursing Students.

\section{Introduction}

In recent years, the number of child abuse cases has increased steadily with a total of 33,532 cases of suspected child abuse reported by 60 child protection agencies nationwide in $2018^{[1]}$. To prevent child abuse, which is continuously increasing, early detection of abuse cases can be the best way to save children from the greater damage. As the preventive measure against child abuse, the government is trying to find and protect

\footnotetext{
Corresponding Author:

Dahye Park

Professor, Department of Nursing, Semyung University, Jecheon-si, Chungbuk, 27136, Korea

e-mail: dhpark@semyun.ac.kr

Phone Number: 82-43-649-1588
}

abused children early and as part of this, the reporting system of child abuse can be found ${ }^{[2]}$. Reports by person in occupations that are likely to discover child abuse play an important role in prevention of child abuse ${ }^{[3]}$.

Nurses are included in the report duty of 24 occupations specified in the Special Act on Punishment of Child Abuse Crimes, etc.and are obliged to report to child protection agencies or investigation agencies if they become aware or suspect of child abuse crimes while performing their duties ${ }^{[4]}$. In particular, nurses frequently come into contact with children of all ages due to their special characteristics such as immunization, growth test and development evaluation. Therefore, they should play the most important role in identifying and reporting abuse among occupations of reporters ${ }^{[5]}$.

It has been reported that the obstacles that hinder child abuse reporting are the symptoms and signs of abuse or lack of knowledge of the reporting process and 
legal process ${ }^{[6]}$, attitudes that it was not serious enough to report or would not help ${ }^{[7,8]}$ and perceptions such as the thought that it will have a negative effect on parents or children and that parenting is the parent's own authority and cannot be interfered with ${ }^{[9,10]}$ are preventing report.

Even in this situation, education and guidelines on child abuse for nurses are insufficient. This condition is due to the lack of clear agreement on the role of nurses in child protection and prevention of abuse, as well as the limited view that the role is still needed only at the individual level or in some areas of care. However, considering that all nurses, as well as nurses specialized in child care, are required to report child abuse and this duty is one of the important roles of nurses, it is urgent to provide education and guidance for nurses. In addition, the need for accurate education should be further emphasized to consider that the reason for the low report rate of nurses is that they do not accurately identify abused children and that they are afraid of legal liability.

Nursing students as well as nurses should be subject to systematic education of child abuse. Therefore, we intend to use this study as a basis for improving awareness and early detection of child abuse and to prepare the basic data for education of nursing students.

The purpose of the study is as follows.

- To grasp the general characteristics of nursing students

- To grasp awareness, knowledge and attitudes on child abuse by nursing students.

- To grasp perception, knowledge and attitudes of child abuse according to the general characteristics of nursing students.

- To grasp the correlation between child abuse awareness, knowledge and attitude of nursing students.

- To identify the factors influencing the attitude of child abuse in nursing students.

\section{Method}

Research Method: This study is a descriptive research study to confirm perception, knowledge and attitude on child abuse in nursing students.

Data collection: The period of data collection was from February 15 to March 13, 2020. The online survey was conducted for 299 nursing college students who understood the purpose of the study and agreed to participate. For ethical consideration of the study subjects, data was collected after approval through the deliberation(IRB No: D **-2020-01-004-02) of Institutional Review Board (IRB) of D university. In addition, approval for using the tool in the study was obtained from its developer. The research assistant without conflict of interest explained the purpose, the method, the outcome and the potential problems of the study to the subjects and explained that they may wish to remain anonymous and refuse to participate if they do not. The survey was conducted after obtaining the informed consent from subjects who agreed to participate in the study and the complimentary product was provided in return.

Research Tools: The survey consisted of general characteristics and child abuse perception (38 questions) [11], knowledge (13 questions) $)^{[12]}$ and attitude (11 questions) ${ }^{[13]}$.

Awareness of Child Abuse: In order to grasp the awareness of child abuse among college students, the child abuse awareness tool developed by Korea Institute for Health and Social Affairs(KIHASA) was used ${ }^{[11]}$. This tool consists of 12 questions of physical abuse, 9 questions of mental abuse, 10 questions of neglect and 7 questions of sexual abuse. In addition, the higher the score from 0 "not abuse at all" to 4 for "definite abuse" on 5-point Likert scale, the higher the awareness of child abuse. At the time of development, the tool's Cronbach's $\alpha$ was .95 and the tool's Cronbach's was 89 for this study.

Knowledge of Child Abuse: The knowledge of child abuse was measured using the knowledge scale of the Child Abuse Report Intention Scale[CARIS], totaling 13 questions ${ }^{[12]}$. For each question, one point was given only for the correct answer and if the answer was 'I don't know' or the answer was incorrect, it was treated as an incorrect answer and given a score of 0 , then the scores for the 13 questions were combined and used as the knowledge score. The Cronbach's $\alpha$ of the original tool was .61 and the Cronbach's $\alpha$ of the tool for this study was .63 .

Attitudes towards Child Abuse: Questions about child abuse attitudes are whether you think positively or negatively about the act of reporting. The measurement was performed by the knowledge scale of Fraser et al.(a 
total of 11 items $)^{[13]}$. The response method of each item was composed of 5-point Likert form( 1 point $=$ not at all, 5 points $=$ very so) and the scores for 11 items were added and used as the attitude score. The Cronbach's $\alpha$ was .84 for the original tool and .80 for the tool of this study.

Data analysis: The collected data were analyzed with SPSS 25.0 and general characteristics of the subjects were identified by frequency, percentage, mean and standard deviation. According to characteristics of the main variables, recognition, knowledge and attitude were analyzed by t-test and ANOVA while the posttest being analyzed by Scheffe' test. The correlation between variables was obtained by Pearson's correlation coefficients. The multiple regression analysis was used to identify the extent and factors affecting the attitudes of child abuse.

Table 1. Differences in Awareness, Knowledge and Attitude on Child Abuse according to General Characteristics $(\mathbf{N}=\mathbf{2 9 9})$

\begin{tabular}{|c|c|c|c|c|c|c|c|c|}
\hline \multirow{2}{*}{ Variables } & \multirow{2}{*}{ Categories } & \multirow{2}{*}{$\mathbf{n}(\%)$} & \multicolumn{2}{|c|}{ Awareness } & \multicolumn{2}{|c|}{ Knowledge } & \multicolumn{2}{|c|}{ Attitude } \\
\hline & & & Mean \pm SD & $\mathbf{t} / \mathbf{F}(p)$ & $\operatorname{Mean} \pm$ SD & $\mathbf{t} / \mathbf{F}(p)$ & Mean \pm SD & $\mathbf{t} / \mathbf{F}(p)$ \\
\hline \multirow{2}{*}{ Gender } & Male & $45(15.1)$ & $173.29 \pm 11.71$ & \multirow{2}{*}{$2.12(.146)$} & $4.42 \pm 2.36$ & \multirow{2}{*}{$4.52(.034)^{*}$} & $28.51 \pm 8.51$ & \multirow{2}{*}{$.22(.636)$} \\
\hline & Female & $254(84.9)$ & $175.80 \pm 10.47$ & & $3.80 \pm 1.70$ & & $29.02 \pm 6.18$ & \\
\hline \multirow{2}{*}{ Religion } & Yes & $113(37.8)$ & $176.69 \pm 10.97$ & \multirow{2}{*}{$2.55(.111)$} & $4.15 \pm 1.91$ & \multirow{2}{*}{$3.71(.055)$} & $29.17 \pm 7.36$ & \multirow{2}{*}{$.21(.640)$} \\
\hline & No & $186(62.2)$ & $174.66 \pm 10.46$ & & $3.73 \pm 1.77$ & & $28.80 \pm 6.05$ & \\
\hline \multirow{2}{*}{$\begin{array}{l}\text { Experience of being } \\
\text { abused }\end{array}$} & Yes & $19(6.4)$ & $172.58 \pm 10.06$ & \multirow{2}{*}{$1.44(.231)$} & $3.79 \pm 1.78$ & \multirow{2}{*}{$.06(.806)$} & $29.00 \pm 6.60$ & \multirow{2}{*}{$1.44(.231)$} \\
\hline & No & $280(93.6)$ & $175.62 \pm 10.72$ & & $3.90 \pm 1.83$ & & $28.94 \pm 6.58$ & \\
\hline \multirow{2}{*}{$\begin{array}{l}\text { Experience of } \\
\text { education }\end{array}$} & Yes & $106(35.5)$ & $176.92 \pm 11.22$ & \multirow{2}{*}{$3.21(.074)$} & $3.86 \pm 1.61$ & \multirow{2}{*}{$.04(.828)$} & $29.24 \pm 6.23$ & \multirow{2}{*}{$.33(.565)$} \\
\hline & No & $193(64.5)$ & $174.61 \pm 10.32$ & & $3.91 \pm 1.94$ & & $28.78 \pm 6.75$ & \\
\hline \multirow{5}{*}{$\begin{array}{l}\text { Frequency of child } \\
\text { abuse education }\end{array}$} & 0 & $195(65.2)$ & $174.73 \pm 10.35$ & \multirow{5}{*}{$0.74(.559)$} & $3.92 \pm 1.94$ & \multirow{5}{*}{$.64(.646)$} & $28.72 \pm 6.75$ & \multirow{5}{*}{$2.04(.088)$} \\
\hline & 1 & $37(12.4)$ & $176.73 \pm 11.21$ & & $4.16 \pm 1.96$ & & $27.38 \pm 6.37$ & \\
\hline & 2 & $36(12.0)$ & $175.78 \pm 11.98$ & & $3.78 \pm 1.26$ & & $30.33 \pm 4.94$ & \\
\hline & 3 & $26(8.4)$ & $178.04 \pm 10.06$ & & $3.44 \pm 1.53$ & & $31.44 \pm 6.55$ & \\
\hline & 4 & $5(2.0)$ & $176.83 \pm 13.67$ & & $3.83 \pm 1.47$ & & $27.00 \pm 8.09$ & \\
\hline
\end{tabular}

Table 2. Nursing Students' Awareness, Knowledge and Attitude on Child Abuse ( $\mathbf{N}=299)$

\begin{tabular}{|l|c|c|}
\hline Variables & Categories & Mean \pm SD \\
\hline & Total & $4.61 \pm 0.28$ \\
& & $4.75 \pm 0.22$ \\
Awareness & Physical & $4.67 \pm 0.40$ \\
& Emotional & $4.18 \pm 0.61$ \\
& Neglect & $4.91 \pm 0.18$ \\
\hline Knowledge & Sexual & $3.89 \pm 1.83$ \\
\hline Attitude & & $28.94 \pm 6.57$ \\
\hline
\end{tabular}


Correlation between the number of education, perceptions, knowledge and attitudes on the subject's child abuse: The number of education related to child abuse was found to be related to perception $(\mathrm{r}=.38, p=.003)$, knowledge $(\mathrm{r}=.45, p=.001)$ and attitude $(\mathrm{r}=.28, p=.004)$. Recognition was confirmed to be related to knowledge $(\mathrm{r}=.49, \mathrm{p}=.001)$ and attitude $(\mathrm{r}=.15$, $p=.007)$. Knowledge and attitude also showed the positive correlation $(\mathrm{r}=.35, p=.003)$ (Table 3$)$.

Table 3. Correlations among the Frequency of Child Abuse Related Education, Child Abuse Awareness, Knowledge and Attitude ( $\mathrm{N}=299)$

\begin{tabular}{|l|c|c|c|c|}
\hline \multirow{2}{*}{ Variables } & $\begin{array}{c}\text { Frequency of child } \\
\text { abuse education }\end{array}$ & Awareness & Knowledge & \multirow{2}{*}{ Attitude } \\
\cline { 2 - 5 } & \multicolumn{4}{|c|}{ r(p) } \\
\hline Frequency of child abuse education & 1 & & & \\
\hline Awareness & $.38(.003) *$ & 1 & & \\
\hline Knowledge & $.45(.001)^{*}$ & $.49(.001)^{*}$ & 1 & 1 \\
\hline Attitude & $.28(.004) *$ & $.15(.007)^{*}$ & $.35(.003) *$ & 1 \\
\hline
\end{tabular}

Predicting factors of child abuse attitudes in subjects: The stepwise multiple regression analysis was conducted to identify the predictors of child abuse attitudes. As a result of the analysis, the number of education, the awareness and the knowledge were found to be influential variables in the attitude of child abuse.
Especially, the number of child abuse education showed high $\mathrm{F}$ value. As a result of the final analysis, it was found that the number of education, the awareness and the knowledge accounted for $22.2 \%$ of attitudes toward child abuse $\left(\mathrm{R}^{2} .222, p<.001\right)$ (Table 4$)$.

Table 4. Factors Influencing Child Abuse Attitude (N=299)

\begin{tabular}{|l|c|c|c|c|c|}
\hline & P & Adjusted R2 & t & F & p \\
\hline Frequency of child abuse education & .349 & .122 & 1.039 & 7.768 & $.048 *$ \\
\hline Awareness & .104 & .137 & 1.231 & 1.958 & $.019 *$ \\
\hline Knowledge & .334 & .222 & -.424 & 2.512 & $<.001 * *$ \\
\hline
\end{tabular}

\section{Discussion}

This study attempted to grasp awareness, knowledge and attitudes of child abuse in nursing students and to confirm the correlation between these variables. First, the child abuse awareness score was 175.42 points. Child abuse awareness is known to be influenced by gender, child abuse experience and child abuse prevention education ${ }^{[14,15]}$. In this study, it was found that the score was affected by gender. When analyzing child abuse perception by type, the perception of sexual abuse was the highest with the score of 4.91 out of 5 , followed by physical abuse, mental abuse and neglect. The perception of child abuse also appeared in the same order as in the study of $\mathrm{Ha}^{[14]}$ and Moon ${ }^{[15]}$ using the same tool.

The level of knowledge on child abuse was 3.8 out of 13. Comprehensive research results of Lazenbatt and Freeman ${ }^{[6]}$ for nurses show low overall knowledge of child abuse in nursing students. In addition, the ability to select abused children and the perception of professional content related to legal reporting systems were insufficient. Professional knowledge of child abuse with reporting method should be provided to nursing students as the systematic educational program.

The attitude on child abuse was 28.9 points. Nursing 
students were found to have a high degree of professional responsibility for abused children. In other words, they tended to agree that they should advocate for abused children and that they should work to identify and discover abused children in clinical trials ${ }^{[10,13,16]}$. We need to avoid ambiguous decisions and make reporting more responsible by planning specific strategies for child abuse,

Recognition, knowledge and attitude showed the significant statistical correlation with education frequency as a result of examining the correlation result of child abuse awareness, knowledge, attitudes and the frequency of child abuse-related education, This result is similar to the one of the previous study ${ }^{[17]}$, in which the number of education related to child abuse has the significant effect on attitudes. In this study, it can be confirmed that the attitude toward child abuse can be improved as the experience of education increases. In addition, the perception of child abuse showed the significant positive correlation with knowledge along with attitude. Considering the results of previous studies ${ }^{[17]}$ that the prevention education of child abuse influenced knowledge and attitude through mediation of child abuse perception, education related to child abuse should be provided as the program that can increase the awareness of obligatory medical reporter and influence reporting.

Lastly, the number of education, the awareness and the knowledge about child abuse were influential variables as factors affecting the attitude of child abuse in nursing students. If these factors are considered, the development of the curriculum or the program related to the reporting obligation to prevent child abuse should be prepared in nursing college curriculum to correct knowledge and attitudes about child abuse.

\section{Conclusion}

This study explored perceptions, knowledge, attitudes and correlations of child abuse among premedical reporter, nursing students. The general characteristics of nursing students did not differ in their perceptions and attitudes toward child abuse. In the gender, the child abuse knowledge scores were significantly higher. The awareness of child abuse was highest in the order of sexual, physical, mental and neglect by type. The higher the number of child abuse education, the higher recognition, knowledge and attitude. In addition, the number of education, the awareness and the knowledge on child abuse were found to have the impact on child abuse attitudes.

This study was conducted on nursing college students and has limitations in the generalization of research results. However, the results of this study provide educational and practical usefulness to increase awareness, knowledge and attitudes of child abuse by preliminary medical reporters and the following suggestions are made. First, it is necessary to provide child abuse education repeatedly in the education process of preliminary medical reporter. Second, we suggest the follow-up study that compares and explores the differences and impacts of child abuse perceptions as well as reporting intentions in nurses and health teachers working in clinical practice.

Ethical Clearance: For ethical consideration of the study subjects, data was collected after approval through the deliberation(IRB No: D **-2020-01-004-02) of Institutional Review Board (IRB) of D university. The informed consent was obtained from the subjects before data collection. Confidentiality of data collected was ensured.

\section{Source of Funding: Self-finance}

Conflict of Interest: Nothing specific-can use the study findings with proper citation of authors name.

\section{References}

1. Ministry of Health and Welfare \& National Child Protection Agency. Child Abuse \& Neglect Korea 2018 (No. 11-1352000-002541-01), Seoul: Ministry of Health \& Welfare, 2019; National Child Protection Agency. Available online: http:// www.korea1391.go.kr/new/bbs/board.php?bo_ table=report \& wr_id=9882 (accessed on 24 May 2020).

2. Kim JA. Study on early childhood preservice teachers' cognition of child abuse and child abuse reporting system. The Journal of Cultural Exchange 2014; 3(3): 99-125. https://www.earticle.net/ Article/A318158

3. Lee CH. A study on the obligation to report child abuse crimes. Korean Juvenile Protection Review 2018; 31(1): 157-186. http://www.dbpia.co.kr/ journal/articleDetail?nodeId=NODE07453134

4. National Law Information Center. Law of Child Welfare. 2020. Available online: http://www.law. 
go.kr/lsSc.do?tabMenuId=tab18 \& section $=\quad \&$ eventGubun $=060101 \&$ query $=\% \mathrm{EC} \% 95 \% 84 \% \mathrm{E}$ B\%8F\%99\%EB\%B3\%B5\%EC\%A7\%80\%EB\%B 2\%95\#undefined (accessed on 19 May 2020).

5. Eisbach SS,Driessnack M. Am I sure I want to go down this road? Hesitations in the reporting of child maltreatment by nurses. Journal for Specialists in Pediatric Nursing 2010; 15(4): 317-323. http:// dx.doi.org/10.1111/j.1744 -6155.2010.00259.x

6. Lazenbatt A, Freeman R. Recognizing and reporting child physical abuse: a survey of primary healthcare professionals. Journal of Advanced Nursing 2006; 56(3): 227-236. http://dx.doi.org/10.1111/j.13652648.2006.04030.x

7. Cho YJ, Shin HR. A study on report experience and perception of mandatory reporters. Journal of Korean Society of Child Welfare 2013; 44: 213237.

8. Feng JY, Levine M. Factors associated with intention to report child abuse: a national survey of Taiwanese nurses. Child Abuse \& Neglect 2005;29(7): 783-795. http://dx.doi.org/10.1016/j. chiabu.2004.11.006

9. Crenshaw WB, Crenshaw LM, Lichtenberg JW. When educators confront child abuse: an analysis of the decision to report. Child Abuse \& Neglect 1995; 19(9): 1095-1113. http://dx.doi.org/10.1016/ S0145-2134(95)00071-F

10. Feng JY, Wu YW. Nurses' Intention to report child abuse in Taiwan: A test of the theory of planned behavior. Research in Nursing \& Health 2005; 28 : 337-347. http://dx.doi.org/10.1002/nur20087

11. The Korea Institute for Health and Social Affairs, 1998. Available online: http://repository.kihasa. re.kr:8080/bitstream/201002/285/1/98-04.pdf (accessed on 19 March 2020).

12. Feng JY. Factors associated with nurses' intention to report child abuse: A national survey of Taiwanese nurses. Unpublished doctoral dissertation. University at Buffalo, State University of New York Buffalo, NY, 2003.

13. Fraser JA, MathewsB, Walsh K, Chen L, Dunne M. Factors influencing child abuse and neglect recognition and reporting by nurses: A multivariate analysis. International Journal of Nursing Studies 2010; 47: 146-153. http://dx.doi.org/10.1016/j. ijnurstu.2009.05.01

14. Ha YO. Nursing students' perceptions of child abuse and factors influencing those perceptions. Child Health Nursing Research 2018; 24(2): 178185. http://dx.doi.org/10.4094/chnr.2018.24.2.178

15. Moon JH. Relationship between child abuse experience of childhood and child abuse perception in college students. Korean ParentChild Health Journal 2009; 12(2): 107118. https://www.koreascience.or.kr/article/ JAKO200918741149563.page

16. Ashton V. The relationship between attitudes toward corporal punishment and the perception and reporting of child maltreatment. Child Abuse \& Neglect 2001; 25(3): 389-399. http://dx.doi. org/10.1016/S0145-2134(00)00258-1

17. Kim SI, Kang JY. The effects of child maltreatment prevention education on the intention to report child maltreatment among future mandatory reporters: The mediating effects of knowledge of recognizing and reporting child maltreatment. Center for Social Welfare Research Yonsei University 2017; 55: 373-400. 